\title{
Correlation between transverse expansion and increase in the upper arch perimeter after rapid maxillary expansion
}

\section{Correlação entre expansão transversal e aumento no perímetro do arco dentário após disjunção maxilar}

\author{
Cristiane Aparecida de Assis Claro* \\ Jorge Abrão** \\ Silvia Augusta Braga Reis* \\ Solange Mongelli de Fantini***
}

\begin{abstract}
The purpose of the present study was to assess the correlation between transverse expansion and the increase in upper arch perimeter, after maxillary expansion. Dental casts of eighteen patients were obtained before treatment and again five months after maxillary expansion. Measurements of intermolar width, intercanine width, arch length and arch perimeter were made with a digital caliper on photocopies taken from the dental casts. After assessment of the method error, a multiple regression model was developed following the identification of the best subset of variables. The resulting equation led to the conclusion that the increase in arch perimeter is approximately given by the addition of 0.54 times the intercanine expansion, and 0.87 times the arch length alteration.

DESCRIPTORS: Orthodontics; Palatal expansion technique; Dental arch.
\end{abstract}

\begin{abstract}
RESUMO: O presente estudo avaliou a correlação entre expansão transversal e aumento no perímetro do arco dentário superior, após disjunção maxilar, em dezoito pares de modelos de gesso, obtidos antes e depois de aproximadamente cinco meses da disjunção maxilar. Os modelos foram fotocopiados e as variáveis largura intermolares, largura intercaninos, comprimento e perímetro do arco dentário superior foram mensuradas por meio de paquímetro digital. Depois de verificado o erro do método, um modelo de regressão múltipla foi desenvolvido em seqüência à identificação do melhor conjunto de variáveis. A equação resultante permitiu concluir que o aumento no perímetro do arco é dado pela adição de 0,54 vezes a alteração intercaninos e de 0,87 vezes a alteração no comprimento do arco.

DESCRITORES: Ortodontia; Técnica de expansão palatina; Arcada dentária.
\end{abstract}

\section{INTRODUCTION}

The reduction of the transverse dimension of the mandible and the maxilla is one of the teethcrowding etiological factors. Therefore, expansion will not only restore the proper dental arch range, but it will also provide additional space for subsequent alignment. However, forecasting the arch perimeter increase amount, resulting from expansion procedures, is questionable.

Inference of the dental arch perimeter increase resulting from transverse expansion is a common practice, usually found in planning and treatment protocols ${ }^{9,23}$. Treatment of transverse discrepancies is supposed to promote arch perimeter increase, often allowing overall teeth-crowding correction. Despite the lack of unanimity found in the related literature on the ratios between an increase in transverse dimensions and changes to arch perimeter and arch length, these ratios are used in orthodontic treatment planning and are often associated with the decision to extract or not. However, given the fact that different values have been found, the increase in arch perimeter can be overestimated or underestimated.

Some researchers have studied perimeter changes due to lower dental arch expansion ${ }^{5,7,17-20}$, and some due to expansion of the maxilla ${ }^{1,2,4,11,19}$; while other authors have utilized a linear regression equation to estimate the perimeter incremental amount due to expansion ${ }^{1,2,4}$, and some have inferred this amount based on mean results of the variables ${ }^{5}$.

\footnotetext{
* Doctorate Students; **Associate Professor; ${ }^{* *} \mathrm{PhD}$, Professor - Department of Orthodontics, School of Dentistry, University of São Paulo.
} 
Claro CAA, Abrão J, Reis SAB, Fantini SM. Correlation between transverse expansion and increase in the upper arch perimeter after rapid maxillary expansion. Braz Oral Res 2006;20(1):76-81.

Ricketts et al. ${ }^{21}$ (1982) suggested an increase of $0.25 \mathrm{~mm}$ in the perimeter for every $1 \mathrm{~mm}$ added to the intermolar distance, a ratio of 1:1 regarding the intercanine distance; and a ratio of 2:1 regarding the incisor proclination. The equation established by Adkins et al. ${ }^{1}$ (1990) estimates an arch perimeter increase of $0.7 \mathrm{~mm}$ to every millimeter added to the inter-first premolar distance. However, the equation proposed by Gandini et al. ${ }^{4}$ (1997) states a ratio of 0.88 between perimeter increase and intermolar change.

The mathematical model developed by Germane et al. ${ }^{5}$ (1991) led to the conclusion that an increment of $1 \mathrm{~mm}$ in the lower intermolar distance promotes a gain of $0.27 \mathrm{~mm}$ in arch perimeter. The combination of the increments of $1 \mathrm{~mm}$ in the intermolar distance and $1 \mathrm{~mm}$ in the intercanine distance results in an increase of $0.93 \mathrm{~mm}$ in perimeter; while the simultaneous increase of $1 \mathrm{~mm}$ in the intercanine distance and $1 \mathrm{~mm}$ in arch length leads to a gain of $1.71 \mathrm{~mm}$ in arch perimeter.

Rapid palatal expansion increases arch perimeter, providing space for correction of moderate ( 3 to $4 \mathrm{~mm}$ ) crowding ${ }^{15}$, and allowing spontaneous lower arch expansion ${ }^{13}$. However, the outcome is more favorable when lower expansion is obtained with an appliance prior to rapid palatal expansion, increasing lower arch perimeter and additionally increasing upper expansion capacity, and consequently the upper arch perimeter ${ }^{15}$. The validity of carrying out rapid palatal expansion in the absence of crossbites has lately been questioned, based on the assumption that in such situations it becomes necessary to work on the mandibular arch to coordinate treatment effects. However, expansion of the mandibular arch is unstable .

Rapid palatal expansion followed by fixed appliances promoted an increase of $6.0 \mathrm{~mm}$ in upper arch perimeter and $4.5 \mathrm{~mm}$ in lower arch perimeter ${ }^{14}$.

The aim of this study was to establish a correlation between transverse expansion and an increase in upper arch perimeter after maxillary expansion.

\section{MATERIAL AND METHODS}

The present work used upper arch study casts from eighteen patients with ages ranging from seven to ten years, treated in a private practice. The sample size was defined after statistical analysis of a pilot group, and resulted in eighteen pairs of upper casts obtained before and roughly five months after rapid palatal expansion. The study included only casts provided with first permanent molars, permanent central incisors and deciduous canines, in pretreatment and post-treatment stages, which were considered reference points for the measurement process.

Patients were treated with a bonded acrylic splint expander, featuring the utilization of a hyrax-type screw, with a high opening capacity, and posterior occlusal acrylic coverage.

\section{Measurement method}

Before and after treatment, casts were photocopied based on the paper by Simplício et al. ${ }^{22}$ (1995), which confirmed the reliability of this procedure in the study of occlusogram tracings. Aiming to identify the magnitude of distortion introduced by the copying process, the casts were photocopied side-by-side with a coin, used as a dimensional standard for image size adjustment of the copy machine, so that the coin diameter measured with a digital caliper (accuracy: $0.01 \mathrm{~mm}$ ) on the paper matched the actual coin diameter.

The selected reference points were the same adopted by Adkins et al. ${ }^{1}$ (1990), except for the first bicuspids, which were not included in the present study due to the sample age group. Reference points were marked with a pen (Papermate, ultrafine model, Diadema, Brazil) to assist in locating and reducing potential measurement errors (Figure 1). The reference points were the following:

a) Inner lingual points on the gingival margin of the first upper molars were taken for the

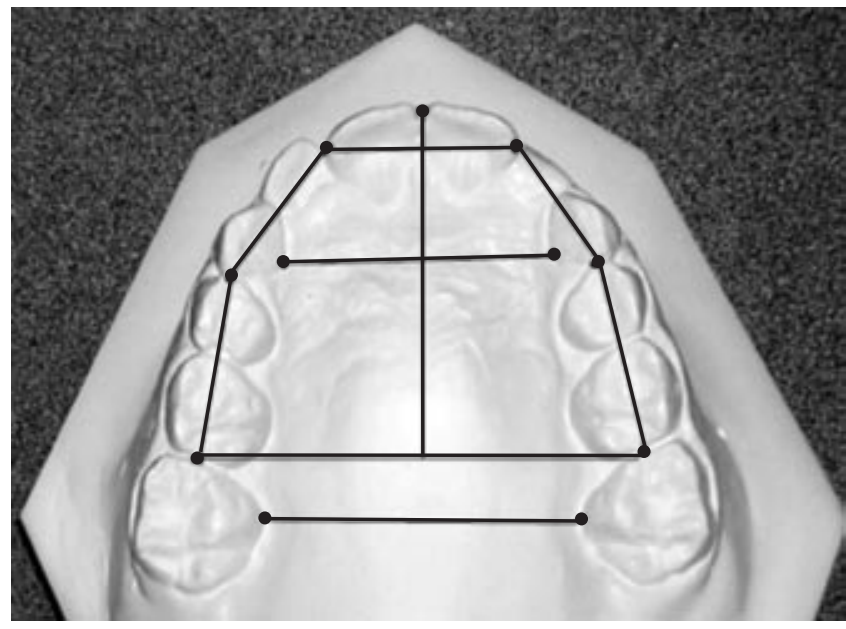

FIGURE 1 - Reference Points. 
Claro CAA, Abrão J, Reis SAB, Fantini SM. Correlation between transverse expansion and increase in the upper arch perimeter after rapid maxillary expansion. Braz Oral Res 2006;20(1):76-81.

TABLE 1 - Results of the Dahlberg test and of the $t$ test.

\begin{tabular}{|c|c|c|c|c|c|c|}
\hline \multirow{2}{*}{ Variable } & \multirow{2}{*}{$\begin{array}{l}\text { Error Variance } \\
\left(\mathrm{Se}^{2}\right)\end{array}$} & \multirow{2}{*}{$\begin{array}{c}\text { Total Variance } \\
\left(\mathrm{St}^{2}\right)\end{array}$} & \multirow{2}{*}{$\begin{array}{l}\text { Reliability Coefficient } \\
{\left[1-\left(\mathrm{Se}^{2} / \mathrm{St}^{2}\right)\right] \times 100}\end{array}$} & \multicolumn{3}{|c|}{$t$ Test (pairwise samples) } \\
\hline & & & & $t$ & $\mathrm{p}$-value & $\mathrm{s} / \mathrm{ns}$ \\
\hline Intermolars pretreatment & 0.013 & 1.98 & 99.34 & -1.21 & 0.29 & $\mathrm{~ns}$ \\
\hline Intermolars post-treatment & 0.013 & 1.72 & 99.24 & -0.51 & 0.63 & ns \\
\hline Intercanines pretreatment & 0.052 & 5.55 & 99.06 & -1.66 & 0.17 & ns \\
\hline Intercanines post-treatment & 0.022 & 1.48 & 98.51 & -1.65 & 0.17 & ns \\
\hline Perimeter pretreatment & 0.122 & 13.69 & 99.10 & -1.94 & 0.06 & ns \\
\hline Perimeter post-treatment & 0.057 & 13.76 & 99.58 & -0.79 & 0.47 & ns \\
\hline Length pretreatment & 0.017 & 6.54 & 99.74 & -0.89 & 0.42 & ns \\
\hline Length post-treatment & 0.008 & 5.88 & 99.86 & -1.55 & 0.19 & $\mathrm{~ns}$ \\
\hline
\end{tabular}

s: significant. ns: not significant.

intermolar width measurement.

b) Inner lingual points on the gingival margin of the deciduous canines were taken for the intercanine width measurement.

c) Points on the mesial aspect of the permanent first molars, on the distal aspect of the canines and of the central incisors were taken for measurement of the arch perimeter.

d) Points on the mesial aspect of the first molars and on the mesial aspect of the central incisors were taken for the measurement of arch length.

Measurements were carried out with a digital caliper (Mitutoyo-Digimatic, Kawasaki, Japan) accuracy of $0.01 \mathrm{~mm}$.

\section{Measurement error}

The same examiner repeated the measurements on $27.77 \%$ of the sample. Random errors of the measurement process were assessed using the Dahlberg test $(1940)^{8}$ followed by the pairwise means $t$ test for identification of systematic errors, if any.

\section{Statistical method}

A significance level of $5 \%$ was adopted. The number of samples was determined after a pilot study and it was similar to the sample size employed by other researchers. Data normality was proved by the Kolmogorov-Smirnov test. The regression model was constructed by employing the best subset practice. Correlation among explanatory variables was identified and properly treated to avoid the undesirable effect of multicollinearity.

\section{RESULTS}

\section{Measurement error assessment}

To evaluate reliability of the measurements, five pairs of casts $(27.77 \%$ of the total sample) were measured twice. All variables were submitted to the Dahlberg test and to the $t$ test. Results, shown in Table 1, revealed that the random error ranged from $0.14 \%$ to $1.49 \%$ (reliability coefficient from $98.51 \%$ to $99.86 \%$ ) and that the systematic error was nonsignificant, confirming the data repeatability.

\section{Sample size calculation}

Before estimating sample size, a pilot lot of 5 samples was taken, resulting in a standard deviation (s) of $0.83 \mathrm{~mm}$ in perimeter change (response variable). By applying the equation $n=\left(16 s^{2} /\right.$ $\left.\mathrm{d}^{2}\right)+1$, with a test power of 0.75 and a difference worth detecting (d) of $0.8 \mathrm{~mm}$, a total of 18 samples was obtained.

\section{Descriptive statistics}

Table 2 shows the variables descriptive statistics.

As dental arch perimeter can be influenced by several factors, the estimate of the contribution of each one to the regression model was investigated by the method of the Best Subsets, and the results are shown in Table 3.

The highest correlations values $\left(r^{2}=0.61\right.$ and $r^{2}$ adj $\left.=0.53\right)$ and $\left(r^{2}=0.60\right.$ and $r^{2}$ adj $\left.=0.55\right)$ have respectively led to the following multiple regression equations:

Perimeter change $=0.37+0.12$ of the intermolar change +0.46 of the intercanine change +0.84 of arch length. 
Claro CAA, Abrão J, Reis SAB, Fantini SM. Correlation between transverse expansion and increase in the upper arch perimeter after rapid maxillary expansion. Braz Oral Res 2006;20(1):76-81.

Perimeter change $=0.77+0.54$ of the intercanine change +0.87 of arch length.

Both equations above are significant at a $\mathrm{p}$ level of $p=0.003$ and $p=0.001$, respectively. However, the second equation was considered more suitable because no multicollinearity was found in the model; that is, the explanatory variables (intermolar change, intercanine change and arch length) were tested one against the other to identify the eventual correlation between them. By testing intermolar and intercanine distance change, a significant correlation was found $(\mathrm{r}=0.66$ and $\mathrm{p}=0.002)$, which was not observed in the intermolar distance change and arch length change $(\mathrm{r}=-0.06$ and $\mathrm{p}=0.797)$, nor in the intercanine distance change and arch length change $(r=-0.36$ and $\mathrm{p}=0.134)$.

\section{DISCUSSION}

The present work assessed patients with mixed dentitions, as it is known that disjunction orthopedic results are more effective within this time span. The studies by Melsen ${ }^{12}$ (1975) and by Ennes, Consolaro ${ }^{3}$ (2004) have revealed a relationship between the complexity increase of the mid-

TABLE 2 - Descriptive statistics for the casts of the patients submitted to rapid palatal expansion $(\mathrm{mm})$.

\begin{tabular}{l|c|c|c|c}
\hline \hline \multicolumn{1}{c|}{ Variable } & Mean & SD & Min. & Max. \\
\hline $\begin{array}{l}\text { Intermolar } \\
\text { distance change }\end{array}$ & 5.48 & 1.2 & 3.4 & 7.2 \\
\hline $\begin{array}{l}\text { Intercanine } \\
\text { distance change }\end{array}$ & 3.59 & 1.39 & 1.05 & 6.8 \\
\hline $\begin{array}{l}\text { Arch perimeter } \\
\text { change }\end{array}$ & 2.41 & 1.14 & 0.63 & 4.59 \\
\hline $\begin{array}{l}\text { Arch length } \\
\text { change }\end{array}$ & -0.37 & 0.93 & -2.13 & 1.79 \\
\hline \hline
\end{tabular}

palatal suture with subject age hindering maxilla separation. Studies to estimate arch perimeter increase from transverse changes after disjunction have dealt with patients in the late transitional or early permanent dentition stage ${ }^{1,2}$.

In this study, an assessment after 5 months was based on the prescription by McNamara and Brudon ${ }^{15}$ which claims that, at this time interval, the midpalatal suture reossification and reorganization have already taken place. The purpose of the present study was to establish the magnitude of the increment in arch perimeter due to transverse changes, and to use this information in treatment planning. For the estimate of the space available for future alignment, only the values related to the end of the appliance stabilization period ( 5 months) were considered. No other device was simultaneously used during this time. However, each patient received orthodontic treatment according to their individual needs after the retention period.

This study did not include a control group, as the authors considered that changes resulting from growing in the time gap of nearly 5 months would be negligible. However, given the statement by Moorrees, Reed ${ }^{16}$ (1964) that the greater intercanine distance change takes place during the replacement of the incisors, it is important to clarify that only in 2 out of the 18 observed patients did the eruption of the lateral incisors take place during this assessment period. The literature review has shown that a control group was also not employed in studies with a purpose similar to that of the present study ${ }^{1,2,4}$.

Research in the literature has shown a notable lack of agreement among authors (see Chart 1), with the application of distinct methodologies.

Previous works by Adkins et al. ${ }^{1}$ (1990) and Akkaya et al. ${ }^{2}$ (1998) have shown that an increase of $1 \mathrm{~mm}$ in the region of the first premolars promotes, respectively, a gain of $0.7 \mathrm{~mm}$ and $0.60-0.65 \mathrm{~mm}$

TABLE 3 - Correlation between explanatory variables and response variable by means of the Best Subsets method.

\begin{tabular}{c|c|c|c|c|c}
\hline \hline \multirow{2}{*}{$\begin{array}{c}\text { Number of } \\
\text { variables }\end{array}$} & \multicolumn{2}{|c|}{ Determination coefficient } & \multirow{2}{*}{$\begin{array}{c}\text { Intermolar } \\
\text { change }\end{array}$} & $\begin{array}{c}\text { Intercanine } \\
\text { change }\end{array}$ & Length change \\
\cline { 2 - 5 } & $\mathrm{r}^{2}$ & $\mathrm{r}^{2}{ }_{\text {adj }}$ & & & $\mathrm{X}$ \\
\hline 1 & 0.22 & 0.17 & $\mathrm{X}$ & $\mathrm{X}$ & \\
\hline 2 & 0.21 & 0.16 & & $\mathrm{X}$ \\
\hline 2 & 0.60 & 0.55 & $\mathrm{X}$ & $\mathrm{X}$ & $\mathrm{X}$ \\
\hline \hline
\end{tabular}


Claro CAA, Abrão J, Reis SAB, Fantini SM. Correlation between transverse expansion and increase in the upper arch perimeter after rapid maxillary expansion. Braz Oral Res 2006;20(1):76-81.

CHART 1 - Perimeter arch relative gain values $(\mathrm{mm})$ resulting from a $1 \mathrm{~mm}$ increase in the intermolar distance, interpremolar distance, intercanine distance and arch length.

\begin{tabular}{|c|c|c|c|c|}
\hline \multirow{2}{*}{ Source } & \multicolumn{4}{|c|}{ Gain ratio from the increase of $1 \mathrm{~mm}$ in the distance: } \\
\hline & Inter molars & Inter premolars & Inter canines & Length \\
\hline Ricketts et al. ${ }^{21}$ (1982) & 0.25 & & 1 & 2 \\
\hline Adkins et al. $^{1}$ (1990) & & 0.7 & & \\
\hline Germane et al. ${ }^{5}$ (1991) & 0.27 & & & \\
\hline Gandini et al. ${ }^{4}$ (1997) & 0.88 & & & \\
\hline Akkaya et al. ${ }^{2}$ (1998) & & 0.6 to 0.65 & & \\
\hline Noroozi et al. ${ }^{19}$ (2002) & 0.3 & & 0.6 & 1 \\
\hline Present study & & & 0.54 & 0.87 \\
\hline
\end{tabular}

in arch perimeter. In the above-mentioned studies, results of orthopedic expansion were evaluated. However, Akkaya et al. ${ }^{2}$ (1998) obtained two equations, one being for rapid maxillary expansion (perimeter change $=0.62+0.65$ times the first premolars width change) and the other for slow maxillary expansion (perimeter change $=0.03+0.60$ times the first premolar width change), with determination coefficients of $r^{2}$ adj $=0.67$ and $r^{2}$ adj $=0.43$, respectively. Equations for the changes after the retention period were developed leading to a perimeter increase ratio of 0.54 times the change in premolar interdistance with the rapid expansion procedure, and 0.52 times the change in premolar interdistance with slow maxillary expansion.

Gandini et al. ${ }^{4}$ (1997) developed a study to assess the results of the orthodontic expansion with a removable expander appliance that led to the following equation: perimeter change $=0.52+0.88$ of the intermolars change with $r=0.57$, therefore with $r^{2}=0.32$, significant at a level of $5 \%$.

It seems controversial that the arch perimeter increase resulting from an increase in intermolar distance $(0.88$ of the intermolar change in the study by Gandini et al. $\left.{ }^{4}, 1997\right)$ is greater than that resulting from a change in the first premolar distance $\left(0.7\right.$ in the study by Adkins et al. ${ }^{1}, 1990$, and 0.6 to 0.65 in the work by Akkaya et al. $\left.{ }^{2}, 1998\right)$. Besides, it is expected that rapid maxillary expansion promotes a greater increase in arch perimeter than expansion with a removable expansion plate, since rapid maxillary expansion promotes the opening of the midpalatal suture with the greatest separation occurring anteriorly.

Ricketts et al. ${ }^{21}$ (1982) forecasts that an increase of $1 \mathrm{~mm}$ in the intermolar distance will result in an increase of $0.25 \mathrm{~mm}$ in arch perimeter, and that an increase of $1 \mathrm{~mm}$ in the intercanine distance will increase arch perimeter by $1 \mathrm{~mm}$, and that an increase of $1 \mathrm{~mm}$ in arch length will promote a gain of $2 \mathrm{~mm}$ in arch perimeter. Such values are practically two times greater than the values found in the present study, that identified a gain of $0.12 \mathrm{~mm}$ in perimeter for every increase of $1 \mathrm{~mm}$ in the intermolar distance. Furthermore, each increase of $1 \mathrm{~mm}$ in the intercanine distance promoted a gain of $0.46 \mathrm{~mm}$ in perimeter, and each increase of $1 \mathrm{~mm}$ in arch length led to a gain of $0.84 \mathrm{~mm}$ in arch perimeter, and eliminating the multicollinearity factor by removing the intermolar distance from the equation, the gain in perimeter was 0.54 times the intercanine distance and 0.87 times the arch length.

The comparison of ratios obtained by the different studies is compromised due to distinct methodologies. Some studies were developed using cast models ${ }^{1,2,4}$, and others used computerized simulations and math analysis ${ }^{5,17-19}$; some evaluated the upper $\operatorname{arch}^{1,2,4}$, and others, the lower $\operatorname{arch}^{5,17-19}$.

It is known that the establishment of regression equations is strongly dependent on a large sample size. Most of the works, including the present one, have been done with a relatively small number of subjects due to the inclusion criteria (age group, presence of specific teeth, appliances of the same type etc). Because of this, the employment of meta-analysis in future studies will be very helpful to the scientific community by increasing sample size, testing statistical power, dealing with the uncertainties of controversial studies and finally responding to questions poorly clarified in individual tests.

Initial arch shape is probably a factor to be considered in subsequent studies, considering that there are indications linking arch shape to distinct space gains in arch perimeter. By means 
Claro CAA, Abrão J, Reis SAB, Fantini SM. Correlation between transverse expansion and increase in the upper arch perimeter after rapid maxillary expansion. Braz Oral Res 2006;20(1):76-81.

of a mathematic-geometric model, Mutinelli et al. ${ }^{18}$ (2000) identified the changes promoted in arch length by proclinating the lower incisor by $1 \mathrm{~mm}$, keeping the intercanine distance, in distinct arch forms. The length increment in the parabolic arch was $1.51 \mathrm{~mm}$, in the elliptical arch, $1.21 \mathrm{~mm}$, in the hyperbolic arch, $1.61 \mathrm{~mm}$, in the circular arch, $1.21 \mathrm{~mm}$, and in the catenary arch, $2.07 \mathrm{~mm}$.

Catenary forms were predominantly found describing the curvature of the upper and lower arches, regardless of facial types ${ }^{10}$.

Future studies will be able to compare the relationship between the increase in arch perimeter

\section{REFERENCES}

1. Adkins MD, Nanda RS, Currier GF. Arch perimeter change on rapid palatal expansion. Am J Orthod Dentofac Orthop 1990;97(3):194-9.

2. Akkaya S, Lorenzon S, Ucem TT. Comparison of dental arch and arch perimeter changes between bonded rapid and slow maxillary expansion procedures. Eur J Orthod 1998;20(3):255-61.

3. Ennes J, Consolaro A. Sutura palatina mediana: avaliação do grau de ossificação em crânios humanos. R Dent Press Ortodon Ortop Facial 2004;9(5):64-73.

4. Gandini Jr LG, Oriqui OR, Riethmueller M, Santos Pinto A, Loffredol CM. Alterações dimensionais dos arcos dentários no tratamento ortodôntico com aparelho expansor removivel. Ortodontia 1997;30(1):39-44.

5. Germane N, Lindauer SJ, Rubenstein LK, Revere JH, Isaacson RJ. Increase in arch perimeter due to orthodontic expansion. Am J Orthod Dentofacial Orthop 1991;100(5):421-7.

6. Gianelly AA. Rapid palatal expansion in the absence of crossbites: Added value? Am J Orthod Dentofacial Orthop 2003;124(4):362-5.

7. Houlsley JA, Nanda RS, Currier F, McCune DE. Stability of transverse expansion in the mandibular arch. Am J Orthod Dentofacial Orthop 2003;124(3):288-93.

8 . Houston WJB. The analysis of errors in orthodontic measurements. Am J Orthod Dentofacial Orthop 1983;83:382-90.

9. Interlandi S. Gráfico Vetorial Ortodôntico (Versão 2002). R Dent Press Ortodon Ortop Facial 2002;7(4):23-42.

10. Kanashiro LK, Vigorito JW. Estudo das formas e dimensões das arcadas dentárias superiores e inferiores em leucodermas, brasileiros, com maloclusão de classe II, divisão 1 e diferentes tipos faciais. Ortodontia 2000;33(2):8-18.

11. Maruyama NE, Paiva JB, Rino Neto J, Novelli MD. Análise do perímetro do arco dentário e da área palatina após expansão rápida da maxila [resumo]. RPG Rev Pos Grad 2002;9(3):275.

12. Melsen B. Palatal growth studied on human autopsy material. A histologic microradiographic study. Am J Orthod 1975;68:42-54. and transverse expansion considering the use of different appliances.

\section{CONCLUSIONS}

Based on the evidence found, and considering the conditions under which the present study was conducted, it could be concluded that the increase in upper arch perimeter was 0.54 times the intercanine expansion and 0.87 times the change in arch length.

The above conclusions may be used during treatment planning as a guideline to estimate upper arch perimeter gain as a consequence of expansion.

13. McLuckie WC. Effects of slow maxillary expansion on mandibular arch width. Am J Orthod Dentofacial Orthop 1994;105(3):317-8.

14. McNamara JA, Baccetti T, Franchi L, Herberger TA. Rapid maxillary expansion followed by fixed appliances: a long-term evaluation of changes in arch dimensions. Angle Orthod 2003;73(4):344-53.

15. McNamara JA, Brudon WL. Tratamiento ortodóncico y ortopédico en la dentición mixta. Ann Arbor: Needham; 1995.

16. Moorrees CF, Reed RB. Changes in dental arch dimensions expressed on the basis of tooth eruption as a measure of biologic age. J Dent Res 1964;44:129-41.

17. Motoyoshi M, Hirabayashi M, Shimazaki T, Namura S. An experimental study on mandibular expansion: increases in arch width and perimeter. Eur J Orthod 2002;24:12530.

18. Mutinelli S, Manfredi M, Cozzani M. A mathematicgeometric model to calculate variation in mandibular arch form. Eur J Orthod 2000;22:113-25.

19. Noroozi H, Djavid GE, Moeinzad H, Teimouri AP. Prediction of arch perimeter changes due to orthodontic treatment. Am J Orthod Dentofacial Orthop 2002;122(6):601-7.

20. Osborn WS, Nanda RS, Currier GF. Mandibular arch perimeter changes with lip bumper treatment. Am J Orthod Dentofacial Orthop 1991;99(6):527-32.

21. Ricketts RM, Roth RH, Chaconas SJ, Schulhof RJ, Engel GA. Orthodontic diagnosis and planning. USA: Rocky Mountain Data Systems; 1982.

22. Simplício AHM, Souza LA, Sakima MT, Martins JCR, Sakima T. Confiabilidade de xerox de modelos de estudo para o traçado de oclusogramas. Ortodontia 1995;28(3):62-7.

23. Vigorito JW. Ortodontia preventiva: pequenos movimentos dentários. Ganhos e manutenção de espaços. In: Vigorito JW. Ortodontia clínica: diagnóstico e terapêuticas. São Paulo: Santa Madonna; 2004. cap. 8. p. 293-339.

Received for publication on Sep 23, 2005 Sent for alterations on Nov 16, 2005 Accepted for publication on Feb 01, 2006 